\title{
Unmet needs for family planning in Sunsari, eastern Nepal
}

\author{
I S Paudel ${ }^{1}$ S S Budhathoki ${ }^{2}$ \\ ${ }^{1}$ Associate Professor, ${ }^{2}$ Junior Resident \\ School of Public Health and Community Medicine \\ B. P. Koirala Institute of Health Sciences, Dharan, Nepal
}

\begin{abstract}
Introduction: The unmet need for family planning is a very useful tool in measuring and predicting the contraceptive needs of a population. Seventeen percent of all married women would prefer to avoid pregnancy but are not using any form of family planning. In less developed countries, about one forth of pregnancies is unintended. Objective: To determine the level of unmet need for family planning and evaluate the factors that influences the unmet needs in Married Women of Reproductive Age (MRWA). Methods: A cross-sectional study of 410 women attending the immunization clinic of B.P.Koirala Institute of Health Sciences, a teaching hospital in Dharan was carried out over 3 months. Results: MRWA had $22 \%, 15 \%$ and $8 \%$ unmet needs for family planning, spacing and limiting births respectively. Health concerns and side effects (30.5\%), husband and family opposition (14\%), uncertainty about child bearing (12.2\%) and inconvenience (10\%) were among the major constraints to the use of contraception. Unmet need has significant association between parity \& education. Age and family type had no significant effect on unmet needs. Conclusion: In spite of high level of awareness about family planning method, a significant level of unmet need exists among women of reproductive age.
\end{abstract}

Keywords: unmet needs, family planning, married women of reproductive age, MRWA

IntroductionUnmet need for family planning refers to fecund women who either wish to postpone the next birth (spacers) or wish to stop child bearing (limiters) but are not using a contraceptive method. More than 100 million women globally especially in less developed countries or about $17 \%$ of all married women, would prefer to avoid pregnancy but are not using any form of family planning. Unmet need for contraception can lead to unintended pregnancies, which pose risks for women, their families and societies. In less developed countries, about one forth of pregnancies is unintended that is, either unwanted or mistimed lead to unsafe abortion. An estimated 18 million unsafe abortions take place each year in

Address for correspondence

Dr Ishwari Sharma Paudel, Phd

Associate Professor

School of Public Health and Community Medicine

B. P. Koirala Institute of Health Sciences, Dharan, Nepal

Email: is_paudel@yahoo.com less developed countries contributing high rates of maternal deaths, and injuries in these regions. In addition, unwanted birth pose risks for children are health and wellbeing and contribute to rapid population growth. Family planning is one of the fundamental pillars of safe motherhood and a reproductive right. The practice of family planning is influenced by several socioeconomic factors, hence its variation between countries and within countries.

Contraceptive prevalence rate in Nepal is $48 \%$ with $24.6 \%$ unmet need for family planning (NDHS 2006). Bhandari et al, (2006) reported $25 \%$ unmet need in Eastern Nepal. ${ }^{5-7}$

There are several reasons for unintended pregnancies. Opposition to family planning (by women, their husbands or others), method related problems, problems related side effects and health concerns, cost and access, lack of knowledge about methods or sources of supply are appeared reasons. 
The numbers of women who do not want another child but are not using any method of contraception and the gap between women's preferences and actions and reasons for unmet need will help to initiate or expand the family planning programs in order to reduce unintended pregnancies and lower their country's fertility rates. Unmet need pose a challenge to family planning program of reaching and serving millions of women whose reproductive attitudes resembles those of contraceptive users but who, for some reasons or combination of reasons, are not using any forms of contraception.

\section{Objectives}

1. To determine the level of unmet need for family planning among MRWA women and

2. To evaluate the factors that influences the unmet need.

\section{Methods}

Four hundred and ten women attending immunization clinic of BPKIHS with their children who gave consent to the study were recruited. With the help of pre-tested, semi structured questionnaires, information on demographic and contraceptive proctors were obtained from the respondents. Data analysis was done with SPSS 15.0 version and statistical relations were explored with chi-square table. A p-value of $<0.05$ at $95 \%$ confidence interval was taken as significant.

This is a descriptive cross sectional study carried out over 3 months at the immunization clinic of BPKIHS, a teaching hospital in Sunsari of eastern Nepal. Ethical clearance was obtained from the institutional review board (IERB).

\section{Results}

Socio-demographic characteristics of the respondents are shown in table 1.

Table 1: Demographic profile of mothers with unmet needs

\begin{tabular}{|l|cc|cc|c|}
\hline \multirow{2}{*}{} & \multicolumn{2}{|c|}{ Total } & \multicolumn{2}{|c|}{ Unmet need } & P value \\
\cline { 2 - 5 } & n & \% & n & \% & \\
\hline Age & & & & & \\
\hline $15-19$ & 75 & 18.3 & 9 & 12.0 & 0.05 \\
$20-24$ & 103 & 25.1 & 21 & 20.4 & \\
$25-29$ & 133 & 32.4 & 33 & 24.8 & \\
\hline
\end{tabular}

\begin{tabular}{|l|cc|cc|c|}
\hline $30-34$ & 77 & 17.3 & 20 & 28.2 & \\
$35+$ & 28 & 6.9 & 10 & 35.7 & \\
\hline Parity & & & & & \\
\hline 1 & 96 & 23.4 & 12 & 12.5 & 0.000 \\
2 & 134 & 32.7 & 23 & 17.2 & \\
3 & 99 & 24.1 & 25 & 25.3 & \\
4 & 58 & 14.1 & 20 & 34.5 & \\
5 \& above & 23 & 5.6 & 13 & 56.5 & \\
\hline Type of Family & & & & & \\
\hline Nuclear & 121 & 53.9 & 44 & 19.9 & 0.92 \\
Joint & 181 & 46.1 & 49 & 25.9 & \\
\hline Education & & & & & \\
\hline Illiterate & 132 & 32.2 & 37 & 28.0 & 0.15 \\
Primary & 102 & 24.9 & 29 & 28.4 & \\
Secondary & 55 & 13.4 & 11 & 20.0 & \\
SLC+ & 121 & 29.5 & 16 & 13.2 & \\
Total & 410 & 100 & 93 & 22.7 & \\
\hline
\end{tabular}

Almost 99 percent of women knew at least one method of contraception, 65 percent women ever used method. (Table not shown)

Most of the respondents (76\%) were within the age range of 25- 29 years; of parity of up to $2(50 \%)$; and were illiterate (32\%).

The major sources of family planning knowledge mentioned are television (32\%) radio (25\%), health worker $(30 \%)$ and friends (24\%) and newspaper (14\%).

Total unmet need for family planning was 21.7 percent; $14.9 \%$ of the women had unmet need for spacing and $7.8 \%$ for limiting births. (Table 1)

Table 1: Demographic profile of mothers with unmet needs

A question related to the benefits of family planning to the women, birth spacing (82\%), limiting birth (63) and healthy mothers child were identified as the main benefits of family planning. (Table 2)

\section{Table 2: Benefits of family planning}

\begin{tabular}{|l|l|}
\hline Birth spacing & $80 \%$ \\
Limiting birth & $63 \%$ \\
Do not know & $2.5 \%$ \\
Healthy mother child & $45 \%$ \\
Reduce maternal death & $3.5 \%$ \\
Prevent unwanted pregnancy & $75 \%$ \\
\hline
\end{tabular}

Opposition from husbands, families and communities (14\%), health concern and side effects $(30.5 \%)$, 
uncertainty about child bearing (12.2\%) were the main reasons for non use of family planning. Significantly large proportion (29\%) of the women did not mention any reason but were using any method of family planning. (Table 3 )

\section{Table 3: Distribution of mother in relation to reasons for unmet need}

\begin{tabular}{|l|r|}
\hline Reasons for unmet need & \% $(\mathbf{n}=\mathbf{4 1 0})$ \\
\hline Opposition from husband/ family/ & \\
community & 14.0 \\
Inconvenience & 10.5 \\
Health concerns and side effects & 30.5 \\
Lack of information & 3.5 \\
Uncertainty about child bearing & 12.2 \\
No specific reason & 29.3 \\
\hline Total & $\mathbf{1 0 0}$ \\
\hline
\end{tabular}

\section{Discussion}

The total unmet need for family planning among women of reproductive age attending immunization clinic of B P Koirala Institute of Health Sciences recorded in this study was $22.7 \%$. This is high but similar to $28 \%$ found in $2001^{5}$ and $24.6 \%$ in $2006^{6}$ in Nepal. Another similar type of study from Nepal reported that $25 \%$ women are in unmet need that $15.5 \%$ for limiting and $9.5 \%$ for spacing ${ }^{7}$ but in this recorded that unmet need for spacing was more as compared to limiting contrasting the previous study. The level of education and economic status of the respondents did not influence the unmet need in this study. This study is hospital based and majority me from young age group. Some studies have shown a direct correlation with socio economic status ${ }^{8}$. Also place of residence has been shown to affect unmet need. That unmet need was higher in rural areas then urban areas. ${ }^{9}$

Age of women, level of education and their parity have some influence on unmet need in this study. Higher the age of the women, higher the proportion of unmet need was observed. More unmet need in joint family and higher parity group was also observed in this study.

It is noted that more than $30 \%$ women were not using any method of contraception even then they do not want any more child because of perceived side effects and health concerns. Fourteen percent women were not using any method because of husband and family opposition. These factors have been observed in some studies especially in developing countries. ${ }^{7}$ Perceived side effects and husband opposition to use family planning method are became a major challenge in family planning programs that leads unplanned pregnancies. This study showed that there was a good knowledge of family planning (more than 98 percent) but there was significant lag between knowledge and use of family planning.

\section{Conclusion}

In spite of high level of awareness about family planning method, a significant level of unmet need exists among women of reproductive age. Age type of family and parity are statistically significant while there is no correlation between unmet need and level of education. Fear of side effects, opposition to family members (husband) and inconvenience in use are the main contributors to the unmet need. It is recommended that proper counseling and involvement of men in family planning programs be designed to improve family planning practice in Nepal.

\section{References}

1. Ministry of Health (Nepal). Nepal Family Health Survey 1996: Main report, Family Planning Division, DOHS Kathmandu, Nepal: Ministry of Health 1997.

2. Shrestha Ashoka, John Stocckel, and Jayanti Man Tuladhar. Factors related to non-use of contraception among couples with an unmet need for family planning, Kathmandu, Nepal: New Era. 1998

3. National Planning Commission Secretariat (NPCS), HMG (Nepal) and UNICEF (Nepal) 1996. Nepal Multiple Indicator Surveillance Health and Nutrition Cycle-I, January-March 1995. Kathmandu, Nepal: NPCS and UNICEF.

4. Ministry of Health (Nepal). Insights on Family Health Issue in Nepal. Family Health Division, Department of Health Sciences, Kathmandu Nepal: Ministry of Health 1997.

5. Ministry of Health (Nepal), New Era, and ORC Macro. Nepal Demographic and Health Survey 2001.Calverton, Maryland, USA: Family Health Division, Ministry of Health; New Era; and ORC Macro 2002.

6. Ministry of Health (Nepal), New Era, and ORC Macro. Nepal Demographic and Health Survey 
2006. Calverton, Maryland, USA: Family Health Division, Ministry of Health; New Era; and ORC Macro 2006.

7. Bhandari GP, Premarajan KC, Jha N, Yadav BK, Paudel IS, Nagesh S. Prevalence and determinants of unmet need for family planning in a district of eastern region of Nepal. Kathmandu Univ. Med. J. 2006; 4(2): 203-210.

8. Shah MA, Shah NM, Chowdhury RI, Menon I (2004). Unmet need for contraception in Kuwait: issues for health care providers. Soc. Sci. Med. 59(8): 1573-1580.

9. Dinc G, Eser E, Cihan UA, Ay S, Pala T, Ergör G, Ozcan C. Fertility preferences, contraceptive behaviors and unmet needs: a gap between urban and suburban parts of a city. Eur. J. Contracept. Reprod. Health Care 2007; 12(1): 86-94.

10. Ashford L (2003). Unmet need for family planning: Recent trends and their implications for programs. Population Reference Bureau.

11. Ikamari LD, Lwanga CK. Correlates of unmet need for contraception in Zambia. Afr. J. Health. Sci. 2000; 7(3-4): 12-24.

12. Ross JA, Winfrey WL. Unmet Need for Contraception in the developing world and the Former Soviet Union: An updated estimate. Int. Fam. Plan. Perspect. 2002; 28(3). 